\title{
Safety and efficacy of image-guided enzyme-targeting radiosensitization and intraoperative radiotherapy for locally advanced unresectable pancreatic cancer
}

\author{
AKIHITO NISHIOKA $^{1}$, YASUHIRO OGAWA ${ }^{1}$, KANA MIYATAKE $^{1}$, MICHIKO TADOKORO $^{1}$, \\ MUNENOBU NOGAMI $^{1}$, NORIHIKO HAMADA ${ }^{1}$, KEI KUBOTA ${ }^{1}$, SHINNJI KARIYA ${ }^{1}$, \\ TAKUHIRO KOHSAKI ${ }^{2}$, TOSHIJI SAIBARA ${ }^{2}$, TAKEHIRO OKABAYASHI $^{3}$ and KAZUHIRO HANAZAKI ${ }^{3}$ \\ Departments of ${ }^{1}$ Diagnostic Radiology and Radiation Oncology, ${ }^{2}$ First Internal Medicine and ${ }^{3}$ First Surgery, \\ Kochi University School of Medicine, Kohasu, Okoh-cho, Nankoku-shi, Kochi 783-8505, Japan
}

Received September 13, 2013; Accepted March 20, 2014

DOI: $10.3892 / 01.2014 .2101$

\begin{abstract}
A novel radiosensitization treatment involving the injection of hydrogen peroxide and sodium hyaluronate, using ultrasonic guidance, into a tumor immediately prior to intraoperative radiotherapy (IORT) was established for patients with stage IVa locally advanced unresectable pancreatic cancer. The aim of the present study was to assess the safety and efficacy of this novel treatment, termed Kochi Oxydol-Radiation Therapy for Unresectable Carcinomas-IORT (KORTUC and IORT). In total, 12 patients were treated with KORTUC-IORT, external-beam radiotherapy and systemic chemotherapy using gemcitabine hydrochloride and S-1. For evaluation of the therapeutic and adverse effects, contrast-enhanced computed tomography was conducted prior to the treatment, and one and six months following KORTUC-IORT. Medical examinations were performed every month at the regularly scheduled follow-up visits. The one- and two-year survival rates were 75 and $25 \%$, respectively, and the median survival time was 16 months. All treatments associated with KORTUC-IORT were well-tolerated by the patients, with a small number of adverse effects and no serious complications. It was identified that the delivery of KORTUC-IORT is safe and effective, in combination with external-beam radiotherapy and systemic chemotherapy, for patients with locally advanced unresectable pancreatic cancer.
\end{abstract}

Correspondence to: Dr Akihito Nishioka, Department of Diagnostic Radiology and Radiation Oncology, Kochi University School of Medicine, Kohasu, Okoh-cho, Nankoku-shi, Kochi 783-8505, Japan

E-mail: nishiokaa@kochi-u.ac.jp

Key words: pancreatic cancer, radiosensitizer, hydrogen peroxide, image-guided radiotherapy, enzyme-targeting radiosensitization, intraoperative radiotherapy

\section{Introduction}

In previous experimental studies using the low linear-energy transfer (LET)-radioresistant osteosarcoma cell line, HS-Os-1 (1-3), and the radioresistant prostate cancer cell line, PC-3 (4), it was demonstrated that hydrogen peroxide exhibited strong radiosensitizing effects. Based on these experimental results, a novel radiotherapy technique, Kochi Oxydol-Radiation Therapy for Unresectable Carcinomas, Type-I (KORTUC-I), was developed. It uses hydrogen peroxide and markedly enhances the effects of radiotherapy on various types of superficially exposed and locally advanced neoplasms. Additional radiosensitizing techniques, KORTUC-II and -III, were subsequently developed that used hydrogen peroxide and sodium hyaluronate for intratumoral injection of various types of tumors that are not superficially exposed (Fig. 1). KORTUC-II was approved by the ethics committee of Kochi University (Kochi, Japan) for administration to patients with advanced skin cancers (including malignant melanoma), bone and soft-tissue malignant neoplasms, breast cancer and any type of cancer that had metastasized to the lymph nodes. KORTUC-III was approved for patients with advanced hepatocellular carcinoma. The efficacy of radiotherapy using KORTUC-I and -II has been demonstrated in previous clinical trials (5-8).

Although pancreatic cancer is the 13th most common type of cancer, it is the eigth most common cause of mortality associated with cancer (9). The five-year overall survival rate for pancreatic cancer remains $<5 \%$ (10). The median survival time of patients with localized, but unresectable disease ranges from eight to 10 months (11). Chemotherapy and external-beam radiotherapy (EBRT) are used as palliative treatments for patients when surgical resection is not feasible. Gemcitabine has been the most commonly used chemotherapeutic agent over the past decade and the benefit of its use, as opposed to fluorouracil, has been demonstrated in patients with advanced pancreatic cancer (12). Numerous studies have shown that intraoperative radiotherapy (IORT) provides a marginal increase in the survival rate for patients with localized resectable pancreatic cancer (13), however, the results were not conclusively in favor for patients with locally advanced unresectable pancreatic cancer (14). 
Table I. Patient characteristics.

\begin{tabular}{|c|c|c|c|c|}
\hline Case & $\begin{array}{l}\text { Age, years/ } \\
\text { gender }\end{array}$ & TNM/stage & Location & $\begin{array}{c}\text { Performance } \\
\text { status }\end{array}$ \\
\hline 1 & $62 / \mathrm{F}$ & T4N0M0/IVa & Head & 0 \\
\hline 2 & $60 / \mathrm{F}$ & T4N0M0/IVa & Body & 1 \\
\hline 3 & $71 / \mathrm{F}$ & T4N0M0/IVa & Head & 1 \\
\hline 4 & $58 / \mathrm{F}$ & T4N1M0/IVa & Head & 0 \\
\hline 5 & $72 / \mathrm{M}$ & T4N0M0/IVa & Body & 0 \\
\hline 6 & $68 / \mathrm{M}$ & T4N0M0/IVa & Body & 1 \\
\hline 7 & $72 / \mathrm{F}$ & T4N0M0/IVa & Head & 2 \\
\hline 8 & $68 / \mathrm{M}$ & T4N0M0/IVa & Body & 1 \\
\hline 9 & $75 / \mathrm{F}$ & T4N0M0/IVa & Head & 1 \\
\hline 10 & $79 / \mathrm{F}$ & T4N1M0/IVa & Head & 2 \\
\hline 11 & $67 / \mathrm{M}$ & T4N0M0/IVa & Head & 0 \\
\hline 12 & $78 / \mathrm{M}$ & T4N0M0/IVa & Head & 0 \\
\hline
\end{tabular}

TNM, tumor-node-metastasis; F, female; M, male.

Therefore, a novel radiosensitizer injection technique (KORTUC-IORT) was established for locally advanced unresectable pancreatic cancer, involving the injection of hydrogen peroxide and sodium hyaluronate into the tumor immediately prior to IORT. The aim of the present study was to assess the safety and efficacy of KORTUC-IORT for patients with stage IVa locally advanced unresectable pancreatic cancer.

\section{Patients and methods}

Patients. A total of 12 patients, five males and seven females, were consecutively enrolled in the KORTUC-IORT trial between February 2008 and September 2010. The ages of the patients ranged from 58 to 79 years with a mean of 69.2 years (Table I). Each patient was enrolled subsequent to providing fully informed, written consent. All patients had surgically confirmed stage IVa locally advanced unresectable pancreatic cancer and were treated with KORTUC-IORT, EBRT and systemic chemotherapy.

KORTUC-IORT procedure. KORTUC-IORT involved the injection, under ultrasonic guidance, of a maximum of $9 \mathrm{ml}$ radiosensitizer into the tumor tissue immediately prior to the administration of IORT. The radiosensitizer was prepared by adding $0.5 \mathrm{ml}$ of $3 \%$ hydrogen peroxide solution (Oxydol; Kenei Pharmaceutical, Co., Ltd., Osaka, Japan) into a commercially available disposable syringe containing $2.5 \mathrm{ml}$ of $1.0 \%$ sodium hyaluronate, which is ordinarily used for intra-articular injection in patients with chronic knee joint disorders. Hydrogen peroxide was added immediately prior to use to avoid the degradation of sodium hyaluronate by the oxidative action of hydrogen peroxide. The final concentration was $0.5 \%$ hydrogen peroxide and $0.83 \%$ sodium hyaluronate.

For IORT, the tumors were irradiated at a dose of $25 \mathrm{~Gy}$ in a single fraction with a $12-$ or $15-\mathrm{MeV}$ electron beam using a linear accelerator (ML-15MDX; Mitsubishi Electric, Co., Ltd., Tokyo, Japan) and no tumor resection was performed.
Table II. Unresectable pancreatic cancer treatments.

\begin{tabular}{|c|c|}
\hline Case & Treatment \\
\hline 1 & $\mathrm{~S}-1>\mathrm{EBRT}>\mathrm{KORTUC-IORT}>\mathrm{GEM}+\mathrm{S}-1$ \\
\hline 2 & EBRT $>$ GEM $>$ KORTUC-IORT $>$ GEM+S-1 \\
\hline 3 & GEM+S-1 > KORTUC-IORT > EBRT+GEM > GEM \\
\hline 4 & GEM+S-1 > KORTUC-IORT $>$ EBRT + GEM $>$ GEM + S -1 \\
\hline 5 & GEM > KORTUC-IORT > EBRT+GEM > GEM+S-1 \\
\hline 6 & GEM $>$ KORTUC-IORT $>$ EBRT+GEM $>$ GEM+S-1 \\
\hline 7 & GEM $>$ KORTUC-IORT $>$ EBRT+GEM > GEM+S-1 \\
\hline 8 & KORTUC-IORT > EBRT+GEM > GEM+S-1 \\
\hline 9 & KORTUC-IORT $>$ EBRT+GEM $>$ GEM+S-1 \\
\hline 10 & KORTUC-IORT $>$ EBRT+GEM > GEM+S-1 \\
\hline 11 & GEM $>$ KORTUC-IORT $>$ EBRT+GEM $>$ GEM+S-1 \\
\hline 12 & KORTUC-IORT > EBRT+GEM > GEM+S-1 \\
\hline
\end{tabular}

$>$, followed by; S-1, tegafur, gimestat and otastat potassium; EBRT, external-beam radiotherapy; KORTUC, Kochi Oxydol-Radiation Therapy for Unresectable Carcinomas; IORT, intraoperative radiotherapy; GEM, gemcitabine hydrochloride.

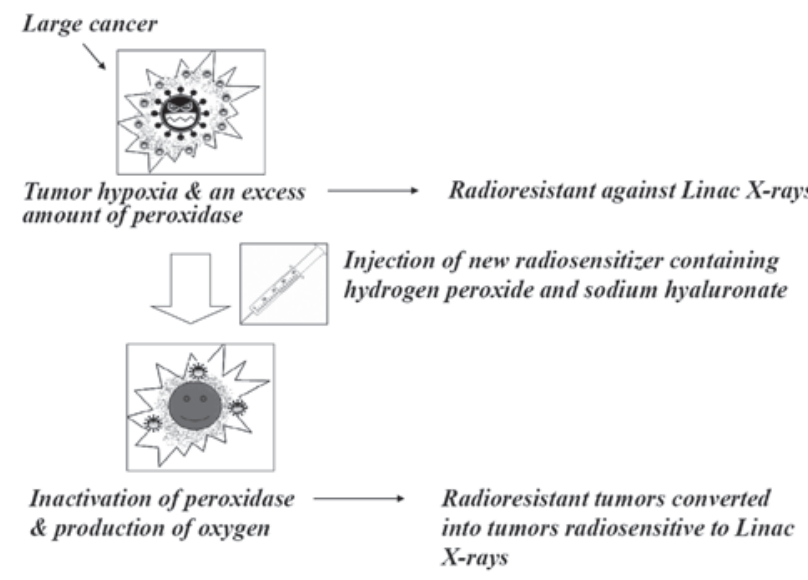

Figure 1. Novel enzyme-targeting radiosensitizing treatment.

For EBRT, patients received radiation to the abdomen five times per week at a dose of $2 \mathrm{~Gy} /$ day in 15 fractions (total dose, $30 \mathrm{~Gy}$ ) using 10-MV X-rays, prior or subsequent to KORTUC-IORT. Chemotherapy was initiated prior or subsequent to administering KORTUC-IORT and was continued for as long as possible. Chemotherapy consisted of gemcitabine hydrochloride administered intravenously once per week at a dose of $300 \mathrm{mg} /$ body weight during EBRT, and $1000 \mathrm{mg} / \mathrm{m}^{2}$ prior or subsequent to radiotherapy with an occasional rest week. S-1, a novel oral anti-cancer agent, is composed of tegafur, gimestat and otastat potassium (15). S-1 was administered orally twice daily at a dose of $80-100 \mathrm{mg} / \mathrm{day}$ for 28 days, followed by 14 days without treatment. This cycle was repeated as many times as necessary and Table II summarizes the treatments for each patient.

Patient follow-up. All patients were examined during regularly scheduled follow-up visits to evaluate the therapeutic and adverse effects of the treatment regimen. Medical and laboratory 
Table III. Adverse effects and tumor markers.

\begin{tabular}{llll}
\hline & & \multicolumn{1}{c}{ Effect on serum level of tumor marker } \\
\cline { 3 - 4 } Case & & Adverse effect & 6 months post treatment \\
\hline 1 & Mild liver dysfunction & Elevated & Decreased \\
2 & None & Decreased & - \\
3 & None & Elevated & Elevated \\
4 & None & Decreased & Elevated \\
5 & None & Elevated & - \\
6 & None & Decreased & Decreased \\
7 & None & Elevated & - \\
8 & Mild liver dysfunction & Decreased & Elevated \\
9 & Mild liver dysfunction & Decreased & Decreased \\
10 & None & Decreased & - \\
11 & None & Decreased & Decreased \\
12 & Mild liver and renal dysfunction & Decreased & Elevated \\
\hline
\end{tabular}

-, not evaluable.

Table IV. Therapeutic effects and patient outcomes.

\begin{tabular}{lccc}
\hline & \multicolumn{2}{c}{ Therapeutic effect } & \multicolumn{2}{c}{ Time until patient } \\
\cline { 2 - 3 } Case & At 1 month & At 6 months & $\begin{array}{c}\text { succumbed, months } \\
\text { succer }\end{array}$ \\
\hline 1 & PD & SD & 33 \\
2 & SD & - & 17 \\
3 & SD & PD & 15 \\
4 & SD & PR & 24 \\
5 & PD & - & 28 \\
6 & PR & PR & 16 \\
7 & SD & - & 8 \\
8 & SD & PD & 10 \\
9 & PD & SD & 13 \\
10 & PR & - & 5 \\
11 & SD & SD & 15 \\
12 & PD & PD & 23 \\
\hline
\end{tabular}

$\mathrm{PD}$, progressive disease; $\mathrm{SD}$, stable disease; PR, partial response; -, not evaluable.

examinations, including the assessment of the tumor markers carcinoembryonic antigen, cancer antigen 19-9, duke pancreatic monoclonal antigen type 2 and S-pancrease-1 antigen, were performed monthly. Contrast-enhanced computed tomography (CE-CT) was also performed immediately prior and subsequent to KORTUC-IORT at one and six months and every six months thereafter. The therapeutic effects of the treatment regimen were assessed using CE-CT according to the response evaluation criteria in solid tumors (16).

Statistical analysis. Survival periods were measured starting from the first day of treatment. The Kaplan-Meier method was used to calculate survival analysis.

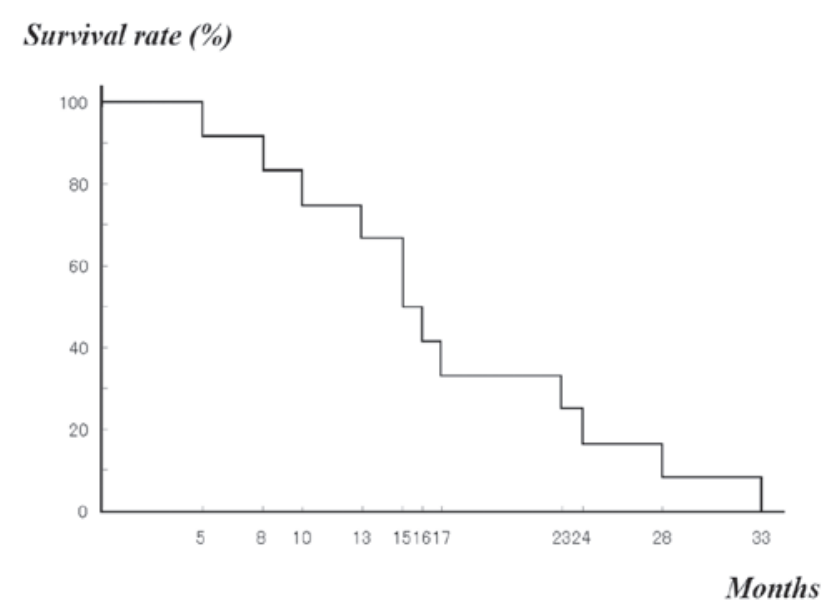

Figure 2. Kaplan-Meier overall survival $(n=12)$.

\section{Results}

KORTUC-IORT is well tolerated and associated with few side-effects. Treatments associated with KORTUC-IORT were well tolerated in all 12 patients, with few adverse effects and no serious complications. The levels of the serum tumor markers were decreased in $75 \%$ of patients (nine of 12 evaluable patients) and in $37.5 \%$ of patients (three of eight evaluable patients) at one and six months following KORTUC-IORT, respectively (Table III). The tumor control rate (partial response plus stable disease) was $67 \%$ (eight of 12 evaluable patients) and $62.5 \%$ (five of eight evaluable patients) at one and six months following KORTUC-IORT, respectively (Table IV).

Patient follow-up. Follow-up periods for all patients ranged between five and 33 months, and the one- and two-year survival rates were 75 and $25 \%$, respectively. The median survival period was 16 months (Table IV and Fig. 2). There 
Table V. Summary of the principal results of previous studies and the present study.

\begin{tabular}{|c|c|c|c|c|c|}
\hline $\begin{array}{l}\text { Author, period } \\
\text { (reference) }\end{array}$ & $\begin{array}{l}\text { Number of } \\
\text { patients }\end{array}$ & Treatment & $\begin{array}{c}\text { One-year } \\
\text { survival rate, \% }\end{array}$ & $\begin{array}{c}\text { Two-year } \\
\text { survival rate, \% }\end{array}$ & $\begin{array}{c}\text { Median survival } \\
\text { time }\end{array}$ \\
\hline $\begin{array}{l}\text { O'Conner et al, } \\
1996-2001(23)\end{array}$ & 68 & $\begin{array}{l}\text { Palliat Surg + IORT } \\
+ \text { EBRT + Chemo }\end{array}$ & - & - & 12 months \\
\hline $\begin{array}{l}\text { Ma et al, } \\
1996-2001 \text { (24) }\end{array}$ & 81 & $\begin{array}{l}\text { Surg + IORT } \\
+ \text { EBRT + Chemo }\end{array}$ & - & - & 12.2 months \\
\hline $\begin{array}{l}\text { Furuse et al, } \\
1995-2001(25)\end{array}$ & 30 & $\begin{array}{l}\text { IORT + EBRT } \\
+ \text { Chemo }\end{array}$ & 57.9 & 0 & 12.9 months \\
\hline $\begin{array}{l}\text { Ogawa et al, } \\
1995-2001(26)\end{array}$ & 144 & $\begin{array}{l}\text { IORT + or - EBRT } \\
+ \text { or - Chemo }\end{array}$ & - & 14.7 & 10.5 months \\
\hline $\begin{array}{l}\text { Sunamura et al, } \\
1999-2002(27)\end{array}$ & 48 & $\begin{array}{l}\text { PR-350 + IORT } \\
+ \text { EBRT }\end{array}$ & 36.4 & - & 318.5 days \\
\hline $\begin{array}{l}\text { Present study, } \\
2008-2010\end{array}$ & 12 & $\begin{array}{l}\text { KORTUC + IORT } \\
+ \text { EBRT + Chemo }\end{array}$ & 75.0 & 25.0 & 16 months \\
\hline
\end{tabular}

Palliat, palliative; Surg, surgery; Chemo, chemotherapy; IORT, intraoperative radiotherapy; EBRT, external-beam radiotherapy; PR-350, novel radiosensitizer; KORTUC, Kochi Oxydol-Radiation Therapy for Unresectable Carcinomas; -, no data.

was no association between outcomes, variations in tumor marker concentrations and therapeutic response.

\section{Discussion}

The present study evaluated the safety and efficacy of KORTUC-IORT, which is a novel radiosensitizer that contains hydrogen peroxide and sodium hyaluronate, in patients with stage IVa locally advanced unresectable pancreatic cancer. All treatments associated with KORTUC-IORT were well tolerated by the patients, with a small number of adverse effects and no severe complications.

During the previous 40 years, various radiosensitizers, including metronidazole, misonidazole, etanidazole and nimorazole, have been established to improve the efficacy of radiotherapy (17-19); however these agents, have not been approved for radiosensitization in clinical practice as they are associated with significant side-effects, including peripheral neuropathy. Various radiosensitizing treatments for radioresistant neoplasms have also been established (20-22). However, clinically applicable methods for administration of these agents have not yet been determined. The novel radiosensitizer that was developed in the present study is considered to be particularly safe. The novel radiosensitizer is intended for direct injection into the tumor, and only contains hydrogen peroxide and sodium hyaluronate, which are not generally associated with severe adverse effects as they are degraded into water and oxygen in the presence of peroxidase and catalase. In addition, the solution is directly injected into tumor tissues thereby targeting peroxidase and catalase, which is present in tumor cells. Therefore, this method represents a novel enzyme-targeting radiosensitization treatment with potential indications for various types of low LET-radioresistant neoplasms.

Previous studies have described the treatment of patients with locally advanced pancreatic cancer using combinations of palliative surgery, IORT, EBRT and chemotherapy. In a case series by O'Connor et al (23), a median survival time of 12 months was reported. In a retrospective cohort study, Ma et al (24) demonstrated a 12.2-month median survival period. In the case series by Furuse et al (25), one- and two-year survival rates of 57.9 and $0 \%$ were reported, respectively, and a median survival period of 12.9 months. Ogawa et al (26) retrospectively analyzed the results of IORT and EBRT performed with or without chemotherapy for patients exhibiting unresectable pancreatic cancer and reported that the two-year overall survival rate and median survival time were $14.7 \%$ and 10.5 months, respectively. Using PR-350 as a radiosensitizing treatment, Sunamura et al (27) treated locally advanced pancreatic cancer with EBRT and IORT. The study reported a one-year survival rate of $36.4 \%$ and a median survival time of 318.5 days. In the present study of 12 patients with stage IVa unresectable pancreatic cancer, the one- and two-year survival rates were 75 and $25 \%$, respectively, and the median survival time was 16 months (Table V). Although the number of patients was small and the follow-up period was short, these results appear to be promising when compared with those that were observed in previous studies. Therefore, the novel radiosensitizing treatment, KORTUC-IORT, is considered to be effective for patients with locally advanced unresectable pancreatic cancer.

In conclusion, KORTUC-IORT may be delivered safely and effectively in combination with current therapies for patients with locally advanced unresectable pancreatic cancer.

\section{Acknowledgements}

The majority of the figures and tables have previously been published online as a poster for the American Society for Radiation Oncology 2012 (http://astro2012.abstractsnet.com/handouts/pdfs/010399.pdf).

\section{References}

1. Ogawa Y, Takahashi T, Kobayashi T, et al: Mechanism of apoptotic resistance of human osteosarcoma cell line, HS-Os-1, against irradiation. Int J Mol Med 12: 453-458, 2003. 
2. Ogawa Y, Takahashi T, Kobayashi T, et al: Apoptotic-resistance of the human osteosarcoma cell line HS-Os-1 to irradiation is converted to apoptotic-susceptibility by hydrogen peroxide: a potent role of hydrogen peroxide as a new radiosensitizer. Int J Mol Med 12: 845-850, 2003.

3. Ogawa Y, Takahashi T, Kobayashi T, et al: Immunocytochemical characteristics of human osteosarcoma cell line HS-Os-1: possible implication in apoptotic resistance against irradiation. Int J Mol Med 14: 397-403, 2004

4. Kariya S, Sawada K, Kobayashi T, et al: Combination treatment of hydrogen peroxide and X-rays induces apoptosis in human prostate cancer PC-3 cells. Int J Radiat Oncol Biol Phys 75: 449-454, 2009.

5. Ogawa Y, Ue H, Tsuzuki K, et al: New radiosensitization treatment (KORTUC I) using hydrogen peroxide solution-soaked gauze bolus for unresectable and superficially exposed neoplasms. Oncol Rep 19: 1389-1394, 2008

6. Ogawa Y, Kubota K, Ue H, et al: Phase I study of a new radiosensitizer containing hydrogen peroxide and sodium hyaluronate for topical tumor injection: a new enzyme-targeting radiosensitization treatment, Kochi Oxydol-Radiation Therapy for Unresectable Carcinomas, Type II (KORTUC II). Int J Oncol 34: 609-618, 2009.

7. Miyatake K, Kubota K, Ogawa Y, et al: Non-surgical care for locally advanced breast cancer: radiologically assessed therapeutic outcome of a new enzyme-targeting radiosensitization treatment, Kochi Oxydol-Radiation Therapy for Unresectable Carcinomas, Type II (KORTUC II) with systemic chemotherapy. Oncol Rep 24: 1161-1168, 2010.

8. Ogawa Y, Kubota K, Ue H, et al: Safety and effectiveness of a new enzyme-targeting radiosensitization treatment (KORTUC II) for intratumoral injection for low-LET radioresistant tumors. Int J Oncol 39: 553-560, 2011.

9. Parkin DM, Bray F, Ferlay J, et al: Global cancer statistics, 2002. CA Cancer J Clin 55: 74-108, 2005.

10. Jemal A, Siegel R, Ward E, et al: Cancer statistics, 2008. CA Cancer $\mathrm{J}$ Clin 58: 71-96, 2008

11. Philip PA, Mooney M,Jaffe D, et al: Consensus report of the national cancer institute clinical trials planning meeting on pancreas cancer treatment. J Clin Oncol 27: 5660-5669, 2009.

12. Burris HA III, Moore MJ, Andersen J, et al: Improvements in survival and clinical benefit with gemcitabine as first-line therapy for patients with advanced pancreas cancer: a randomized trial. J Clin Oncol 15: 2403-2413, 1997.

13. Yamaguchi K, Nakamura K, Kobayashi K, et al: ERT following IORT improves survival of patients with respectable pancreatic cancer. Hepatogastroenterology 52: 1244-1249, 2005.

14. Ruano-Ravina A, Almazán Ortega R, and Guedea F: Intraoperative radiotherapy in pancreatic cancer: a systematic review. Radiother Oncol 87: 318-325, 2008.
15. Shirasaka T, Shimamato Y, Ohshimo H, et al: Development of a novel form of an oral 5-fluorouracil derivative (S-1) directed to the potentiation of the tumor selective cytotoxicity of 5-fluorouracil by two biochemical modulators. Anticancer Drugs 7: 548-557, 1996.

16. Therasse P, Arbuck SG, Eisenhauer EA, et al: New guidelines to evaluate the response to treatment in solid tumors. European Organization for Research and Treatment of Cancer, National Cancer Institute of the United States, National Cancer Institute of Canada. J Natl Cancer Inst 92: 205-216, 2000.

17. Jette DC, Wiebe LI and Chapman JD: Synthesis and in vivo studies of the radiosensitizer 4-[82Br] bromomisonidazole. Int J Nucl Med Biol 10: 205-210, 1983

18. Coleman CN: Hypoxic cell radiosensitizers: expectations and progress in drug development. Int J Radiat Oncol Biol Phys 11: 323-329, 1985.

19. Hall EJ: Oxygen effect and reoxygenation. In: Radiobiology for the Radiologist. Hall EJ (ed). 5th edition. J.B. Lippincott Co., Philadelphia, PA, pp91-111, 2000.

20. Lawrence TS, Blackstock AW and McGinn C: The mechanism of action of radiosensitization of conventional chemotherapeutic agents. Semin Radiat Oncol 13: 13-21, 2003.

21. Choy $\mathrm{H}$ and Milas L: Enhancing radiotherapy with cyclooxygenase- 2 enzyme inhibitors: a rational advance? J Natl Cancer Inst 95: 1440-1452, 2003.

22. Overgaad J: Clinical evaluation of nitroimidazoles as modifiers of hypoxia in solid tumors. Oncol Res 6: 509-518, 1994.

23. O'Connor JK, Sause WT, Hazard LJ, et al: Survival after attempted surgical resection and intraoperative radiation therapy for pancreatic and periampllary adenocarcinoma. Int J Radiat Oncol Biol Phys 63: 1060-1066, 2005.

24. Ma HB, Di ZL, Wang XJ, et al: Effect of intraoperative radiotherapy combined with external beam radiotherapy following internal drainage for advanced pancreatic cancer. World J Gastroenterol 10: 1669-1771, 2004.

25. Furuse J, Kinoshita T, Kawashima M, et al: Intraoperative and conformal external-beam radiation therapy with protracted 5-fluorouracil infusion in patients with locally advanced pancreatic carcinoma. Cancer 97: 1346-1352, 2003.

26. Ogawa K, Karasawa K, Ito Y, et al; JROSG Working Subgroup of Gastrointestinal Cancers: Intraoperative radiotherapy for unresectable pancreatic cancer: a multi-institutional retrospective analysis of 144 patients. Int J Radiat Oncol Biol Phys 80: 111-118, 2011.

27. Sunamura M, Karasawa K, Okamoto A, et al; PR-350 study group: Phase III trial of radiosensitizer PR-350 combined with intraoperative radiotherapy for the treatment of locally advanced pancreatic cancer. Pancreas 28: 330-334, 2004. 